\title{
Properties of oriented strand board made from Betung bamboo (Dendrocalamus asper (Schultes.f) Backer ex Heyne).
}

\begin{abstract}
Bamboo has gained increasing attention as an alternative raw material for use in the manufacture of composite boards. Three-layer OSBs were made using Betung bamboo (Dendrocalamus asper (Schultes.f) Backer ex Heyne) strands to evaluate the effects of strand length and pre-treatment techniques on the physical, mechanical, and durability properties. Three different strand lengths, namely 50, 60, and $70 \mathrm{~mm}$, were prepared. Prior to the manufacture into OSB, the strands were immersed in cold water for $24 \mathrm{~h}$ and in $6 \%$ acetic anhydrides solution for $48 \mathrm{~h}$. The OSBs were fabricated using 5\% MDI resin based on the strand dry weight. The results indicated that MOR and MOE values in perpendicular to the grain direction were much influenced by strand length. The dimensional stability of OSB was slightly improved by immersing the strands in acetic anhydride solution. Immersing strands in cold water and acetic anhydride solution improved the resistance of OSB against subterranean termite (Macrotermes gylvus) attack under the adopted experimental condition. All OSB parameters manufactured in this experiment were better than the minimum requirement of CSA 0437.0 (Grade O-2) standard.
\end{abstract}

Keyword: Bamboo; Alternative raw material; Composite boards; Dimensional stability; Termite resistance. 